\title{
A Semana de Recepção aos Calouros da Universidade de São Paulo
}

Oswaldo Crivello Junior ${ }^{1 *}$ e Heliodoro Teixeira Bastos Filho ${ }^{2}$

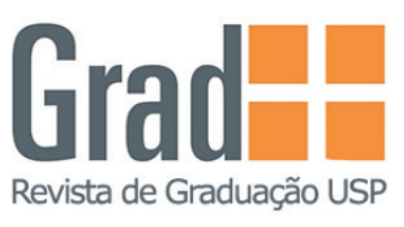

${ }^{1}$ Faculdade de Odontologia da Universidade de São Paulo, ${ }^{2}$ Escola de Comunicações e Artes da Universidade de São Paulo

\footnotetext{
* Autor para correspondência: crivello@usp.br
}

\section{RESUMO}

A Semana de Recepção aos Calouros, atividade oficial da Universidade de São Paulo, é a forma mediante a qual a instituição recebe seus alunos ingressantes. Desde 1999, sublinha os valores que devem ser rapidamente assimilados pelos novos alunos: humanismo, solidariedade, responsabilidade social, ética e respeito absoluto ao ser humano. Atividades de diferentes naturezas promovem o congraçamento entre calouros, veteranos e toda a comunidade acadêmica. Atos violentos são proibidos, mas infelizmente, ainda persistem em alguns casos e devem ser denunciados por meio do serviço telefônico Disque-Trote.

Palavras-chave: Universidade; Ritual de Passagem; Comportamento Social; Violência.

\begin{abstract}
Since 1999 the University of São Paulo performs the Freshmen Welcome (welcome week) for new students. Each course offers different activities, but values such as humanism, solidarity, social responsibility are present. Preventing violence is one of the most important actions in these difficult times. Over these eighteen years we could see the change in our traditions, and acts of violence are exceptions nowadays, but unfortunately there are still people who believe that violence is funny and these behaviors persist as a form of domination.
\end{abstract}

Keywords: University; Social Behavior; Rite of Passage; Violence.

\section{Introdução}

O ingressar na universidade é sempre motivo de alegria para o aluno, assim como para a família e os amigos dele. Trata-se de um sonho realizado, um objetivo alcançado, após mais de uma década de estudos regulares, somados a preparatórios e complementares e, às vezes, só concretizado depois de várias tentativas. É um momento para comemorar e gravar na memória experiências que persistirão para o resto da vida dos aprovados. Para alguns, porém, a recepção se transforma em decepção.

Infelizmente, muitos dos veteranos acreditam que os calouros, após o prêmio pelo esforço de anos de estudo, devam passar por constrangimentos, diferentes tipos de violência, até mesmo físicas, práticas essas definitivamente estranhas ao ambiente universitário. Há as origens e tradições históricas dessas práticas que não são objeto de análise neste relato. Mas, inegavelmente, na segunda década do século XXI, é preciso discutir formas de se combater e, por que não, erradicar essas "tradições", "brincadeiras", "iniciações" (entre outras definições semelhantes) que não condizem com a evolução social, científica, tecnológica, ética e moral da sociedade brasileira, notadamente na universidade.

\section{A Prática da Recepção}

Ainda que as diferentes unidades da USP realizassem algum tipo de atividade para acolher os alunos ingressantes (calouros), foi no final dos anos 1990 que se estabeleceram as diretrizes a serem adotadas na recepção aos ingressantes da 
USP. A Resolução 3143/98 (UNIVERSIDADE DE SÃO PAULO, 1998) institucionalizava a Semana de Recepção aos Calouros, suspendia, na primeira semana letiva, as aulas regulares para os ingressantes e determinava que estas fossem substituídas por atividades programadas em cada unidade, visando a facilitar a assimilação rápida por parte dos calouros dos valores a serem cultivados e estimulados no ambiente universitário: humanismo, solidariedade, universalismo, absoluto respeito ao indivíduo e excelência no aprendizado.

$\mathrm{Na}$ complementação dessas determinações, vinham considerações para que a integração dos alunos ingressantes resultasse do melhor congraçamento possível com os veteranos, e que a conscientização da responsabilidade social, pelo fato de estarem estudando em uma escola pública, isto é, mantida com recursos arrecadados de todos os cidadãos do Estado, deveria ser rapidamente reconhecida e assimilada. Da mesma maneira, advertia que abusos e violências não deveriam estar presentes e que o apoio institucional às festas de recepção somente se justificaria se as atividades a serem desenvolvidas correspondessem aos valores acadêmicos citados. Outro ponto de destaque nessa portaria é o que indica, claramente, que todos os partícipes da universidade, docentes, discentes e funcionários, estariam envolvidos na Semana de Recepção aos Calouros. Paralelamente, as iniciativas realizadas pelos centros acadêmicos seriam integradas à programação geral da unidade.

Ocorre que, no início de 1999, quando pela primeira vez essa resolução vigia, devido à morte de um calouro durante as atividades de recepção realizadas em uma entidade acadêmica da Faculdade de Medicina, acaba-se por proibir, mediante a publicação da GR No 3154/99 (UNIVERSIDADE DE SÃO PAULO, 1999), o trote na USP. Por meio de tal dispositivo, reafirmavam-se diversos pontos da já mencionada resolução 3143/98 e reforçava-se a postura de que a universidade deveria promover a mudança de cultura e banir o trote violento, abusivo ou lesivo à dignidade humana, dentro ou fora do âmbito da instituição.
Como decorrência desse processo, cria-se o Disque-Trote, um serviço telefônico 0800, sem custo para o usuário, cuja finalidade se centra em receber denúncias relacionadas a atividades que desrespeitam o que determinava a Portaria 3143/98. O Disque-Trote pode ser acionado por qualquer cidadão. Não exige identificação, é gratuito, e as denúncias são direcionadas aos professores responsáveis pela unidade citada para as devidas averiguações. Ativo das $8 \mathrm{~h}$ às $21 \mathrm{~h}$, de segunda à sexta, no período de quatro a seis semanas, dependendo do calendário da universidade, o serviço dá retorno sobre os fatos relatados se o denunciante assim o desejar. Diversas chamadas, no entanto, não são caracterizadas como denúncias; entre elas, em geral, há demandas por outras informações, assim como por orientações e mesmo por assuntos não relacionados com a USP. Também há um número expressivo de falsas informações.

Para além de tais linhas de fuga, as denúncias podem ser relatadas pelas próprias vítimas, por testemunhas ou por terceiros. Estudantes de graduação da USP são contratados, treinados e orientados por uma funcionária da universidade para atenderem as chamadas telefônicas. Em vista disso, o serviço tem se mostrado uma ferramenta indispensável para os alunos ingressantes que ainda não conhecem o novo ambiente escolar e as formas de se comunicar com a instituição, além de servir como uma referência de rápida assimilação e uso simplificado.

\section{A Campanha de Recepção aos Calouros}

Ainda no âmbito da acolhida dos alunos ingressantes, no referido ano de 1999, criou-se a Campanha de Recepção aos Calouros. A USP sentiu ser conveniente, naquele momento, o estabelecimento de uma comunicação que orientasse os veteranos a adotarem um comportamento solidário. Tal iniciativa, popularmente conhecida como Campanha do Trote, é feita por alunos da disciplina de Arte Publicitária da Escola de Comunicações e Artes da USP (ECA). Nos primeiros anos, as produções tinham como caracte- 

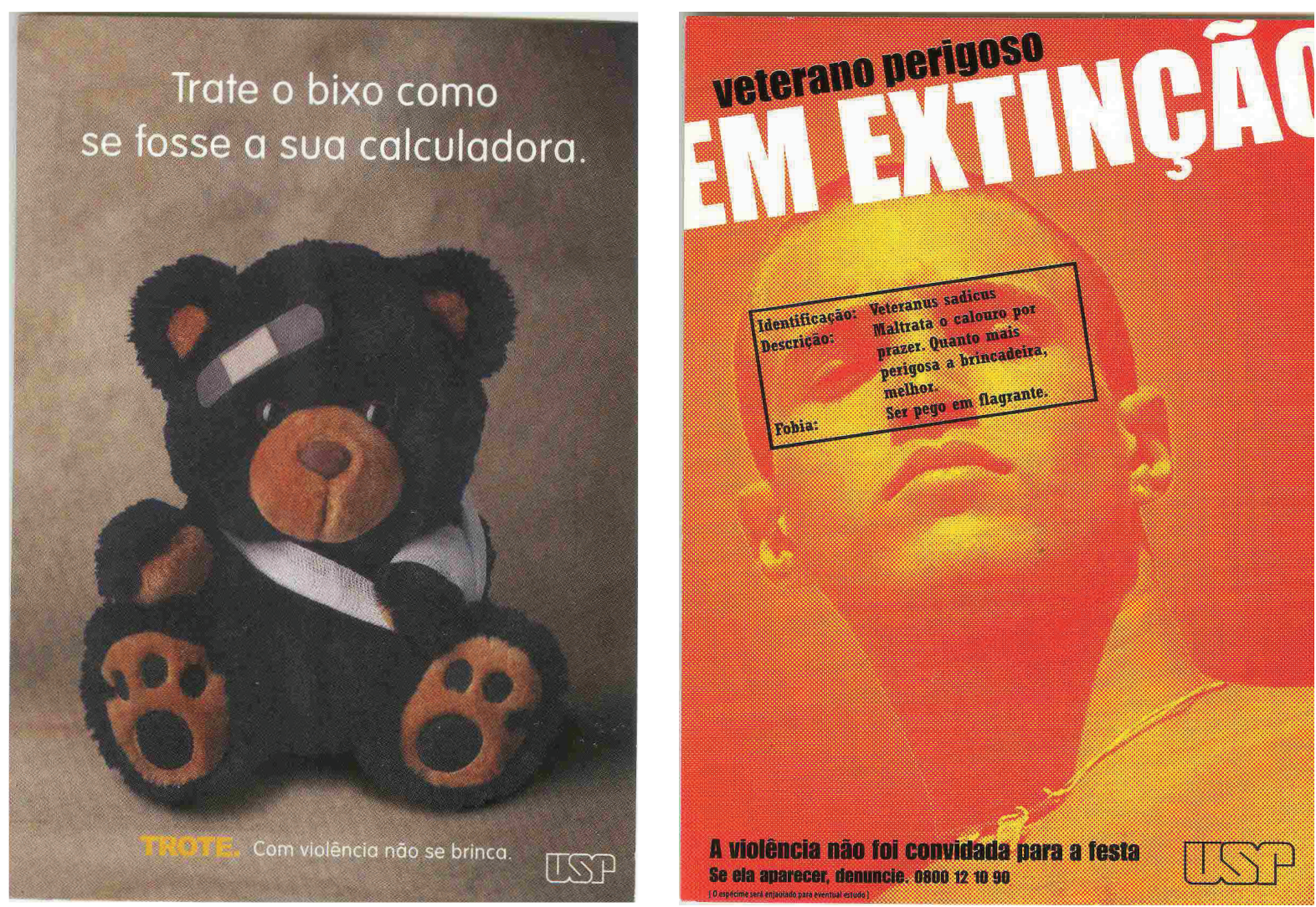

Imagens das Campanhas de Recepção aos Calouros de 2001 ("Trote com Violência Não se Brinca") e de 2002 ("A Violência Não Foi Convidada para Festa”).

rística predominante atingir os alunos veteranos agressores. Com o passar dos anos, as peças passaram a ser direcionadas tanto aos ingressantes quanto aos veteranos. Nesse processo, elas foram se modificando ao longo do tempo: desde mensagens de que o veterano violento não tinha sido convidado para a festa e se aparecesse deveria ser denunciado, até as que advertiam os demais alunos a não estragar a alegria dos que lutaram tanto para entrar na universidade.

Para se compreender a dinâmica da criação das campanhas de recepção dos calouros precisa-se saber que um curso de publicidade é sempre genérico. Até a mensagem publicitária chegar ao público a que se destina, há o envolvimento de vários profissionais que atuam em diferentes áreas, mas apresentam o mesmo objetivo: a construção de mensagens persuasivas, que atinjam de forma eficaz o público. A criação e a direção de arte são áreas importantíssimas na construção da mensagem, mas não são as únicas. Atendimento, planejamento, pesquisa, mídia, por exemplo, são campos com o mesmo grau de importância.

Dessa maneira, não é difícil entender a "generalidade" dos cursos de publicidade. Numa classe de 25 alunos, dois ou três estão propensos a caminhar pela área da arte ou design gráfico. Outros dois ou três têm forte relação com o texto criativo e surgem aí ótimos redatores. E as outras áreas de possível atuação são reveladas e descobertas durante o curso.

Com esse antigo raciocínio em mente, muito em função de experiências adquiridas no mercado, estruturaram-se as disciplinas de Programação Visual e de Arte Publicitária. Mesmo não tendo o desejo e tendência para a área de arte e criação, é fundamental, para um aluno de publicidade, ter conhecimento básico de técnicas, conceitos e teorias que suportam o processo de construção de uma peça de comunicação, passando pela dificuldade e angústia do ato criativo. Se a mensagem não for entendida, não há informação nem comunicação. $\mathrm{E}$ isso vale para 
todas as áreas já citadas. Por exemplo, para um aluno com habilidades gráficas, pensar a mídia estratégica não deve ser o problema dos sonhos a ser resolvido. Mas, novamente, a noção de conceitos e técnicas do assunto, apresenta-se como conhecimento importante. E todos os cursos de publicidade têm essa característica. Todos os alunos devem passar por todas as disciplinas que vão lhe dar os instrumentos necessários para a busca da melhor comunicação.

Em vista disso, ganhou corpo no curso de publicidade da Escola de Comunicações e Artes a ideia de um efetivo trabalho prático no âmbito das referidas disciplinas. De um modo geral, elas "solicitam" tal forma de aprendizado. Mesmo com o foco na direção de arte, tem-se aí a possibilidade de os alunos vivenciarem praticamente todas as áreas de atuação de um publicitário. $\mathrm{E}$ nada melhor do que esse trabalho prático seja real. E quem é que não necessita de uma comunicação criativa, com qualidade e barata? Todos precisam. Foi assim que a Reitoria da USP tornou-se o "maior cliente" da disciplina.

Foram muitos trabalhos com diversos temas. Campanha de doação de sangue para o Hemo-
centro/USP, campanha contra o abandono de animais, campanhas de boas práticas para o CEPEUSP, campanha para a Rádio USP, campanha para Comissão de Direitos Humanos/USP... Enfim, vários temas, sempre institucionais. Mas o trabalho mais presente, e que acontece há 18 anos, diz respeito à Campanha de Recepção aos Calouros da Universidade de São Paulo.

Esta última se mostra interessante, pois os alunos das disciplinas em questão fazem parte da meta do trabalho a ser desenvolvido. Em outras palavras, enquadram-se no público que deve ser atingido. Assim, há grande sensibilidade para o raciocínio de um caminho criativo. O briefing (o problema, o histórico das recepções, o disque trote...) existe. E como no mercado, é examinado por nosso "cliente", que comparece em aula previamente agendada e discursa sobre o assunto, solicitando solução para o problema de comunicação. Com as agências já definidas (os grupos formados pelos alunos), estas se comportam como "verdadeiras" e completam o briefing com perguntas e argumentos.

O cliente é a Pró-reitoria de Graduação. É ela a responsável pela coordenação das ações

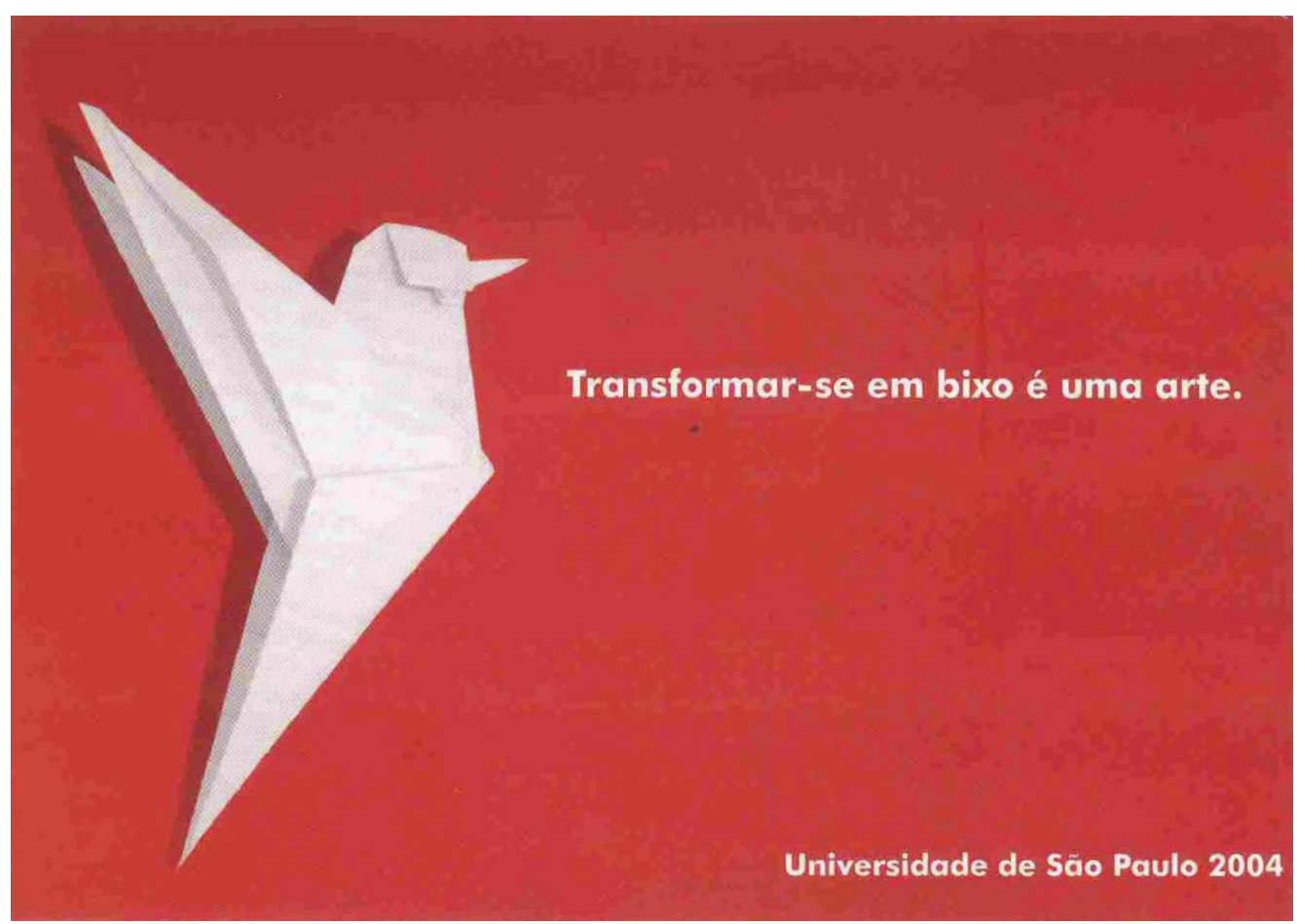

Imagem da Campanha de Recepção aos Calouros de 2004, cujo tema era "Transformar-se em bixo é uma arte". 
na Semana de Recepção aos Calouros. Para as disciplinas, esse trabalho tem uma conhecida presença e importância, uma vez que permite lidar com um tema recorrente e necessário, o qual torna possível a aproximação com todas as áreas profissionais da publicidade. Não por acaso, criam-se as condições para um aprendizado contínuo - desde o início do processo, com a
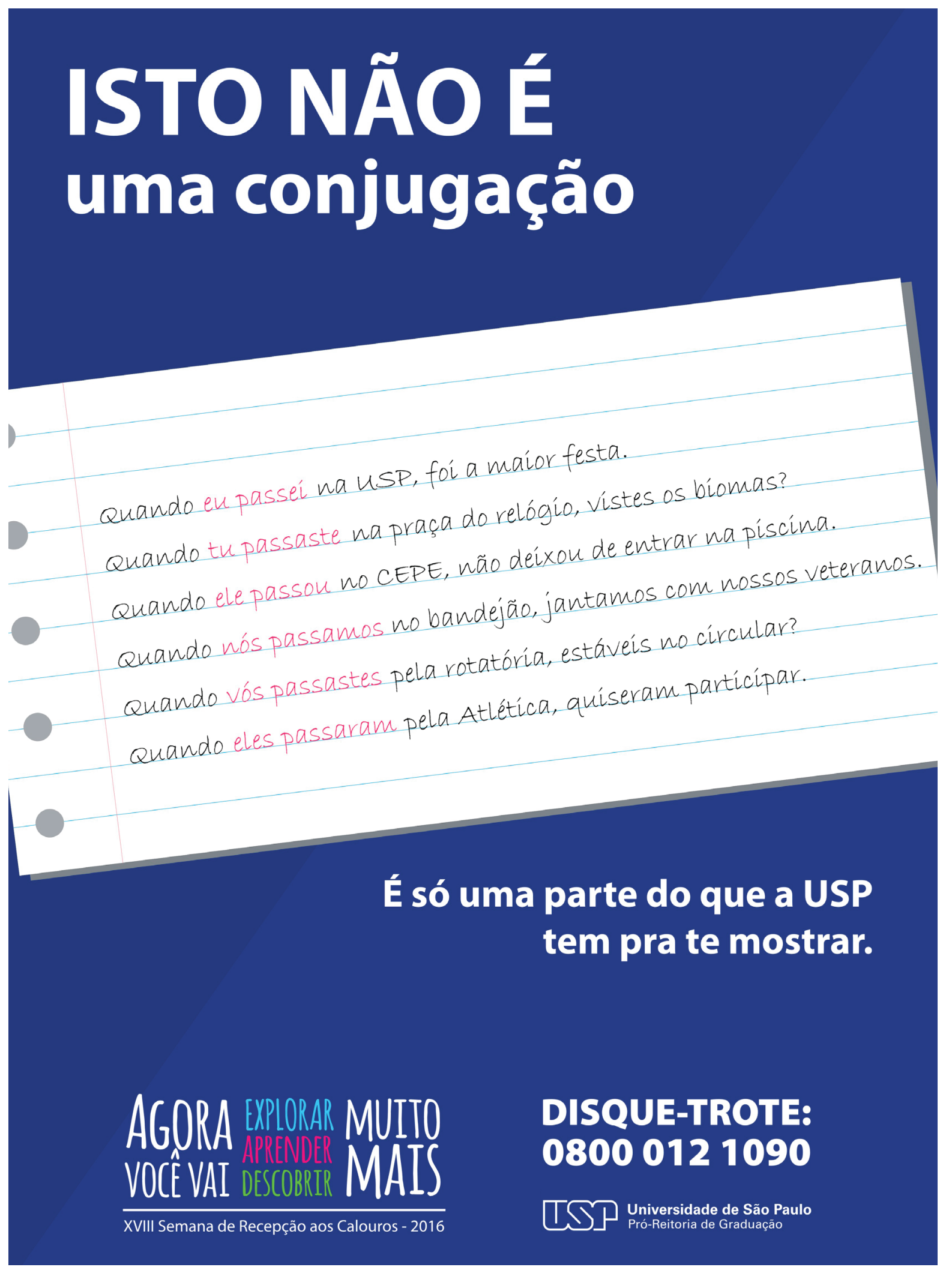

Imagem da Campanha de Recepção aos Calouros de 2016, que apresenta o mote "Agora Você Vai Explorar, Entender, Descobrir Muito Mais". 
construção de um conceito na comunicação, até a noite das apresentações para o cliente - que acontece num espaço fora da sala de aula, onde as duas turmas, manhã e noite, discorrem sobre suas propostas para o cliente e seus convidados. Trata-se, portanto, do dia do "grande aprendizado". Todos os alunos tornam-se conhecedores de todas as propostas.

Para o cliente, fica a satisfação de receber nove ou dez propostas diferentes, a maioria com bons caminhos criativos. Propostas em que se ressaltam o aspecto ético, como cabe à Universidade de São Paulo, e que, ao mesmo tempo, distinguem-se pelo cuidado em relação à produção, com soluções de impacto visual, mas de baixo custo para a finalização.

E por fim, fica ainda para o cliente a difícil missão de optar por apenas uma das propostas, dentre as tantas ideias novas e interessantes que recebe. E lógico, também, como acontece no mercado em concorrências/licitações entre agências, os alunos dos grupos que não tiveram seus trabalhos escolhidos criticarem a decisão da escolha por parte do cliente. É sempre assim. Mas até isso faz parte do aprendizado.

\section{Contraponto e Trote Solidário}

Em relação às atividades voltadas à recepção aos ingressantes desenvolvidas por outras instituições de ensino superior, uma rápida busca na internet nos leva a cartazes cujas características principais remontam a palavras e expressões como alegria, congraçamento, estreitamento de relações interpessoais e, predominantemente, festa. Somente em algumas poucas peças publicitárias existem advertências como o cuidado com o consumo de álcool e a proibição da violência. Outras atividades comumente realizadas resumem-se a palestras com objetivos de conscientização política, mas estas são exceções.

Breve análise desse material nos fez notar que tais cartazes se mostram burocráticos, quase anódinos. Essa talvez tenha sido a característica diferente das campanhas realizadas na USP: elas deveriam provocar uma reação, reflexão por parte dos alunos; marcá-los para que sempre se lembrassem das mensagens então vei- culadas. Além disso, após estudos que mostraram que a evasão ocorre, majoritariamente, no primeiro semestre do curso, buscou-se incentivar os programas de recepção (PENIN, 2008), visando a estimular os ingressantes a se integrarem ao ambiente acadêmico.

Nem sempre as campanhas tiveram a repercussão extramuros que, à primeira vista, parecia que teriam. Um exemplo relacionado a tal quebra de expectativa diz respeito à participação nessas peças publicitárias de pessoas de destaque em diferentes setores da sociedade, formadas pela USP. Inicialmente, achou-se que a haveria grande repercussão da campanha por parte da mídia, o que, efetivamente, não ocorreu. Outro ponto relacionado à perda de impacto por parte de tais iniciativas deveu-se à proibição, pela prefeitura de São Paulo, dos outdoors. Todavia, acredita-se que a iniciativa da Universidade de São Paulo na organização da semana de recepção aos calouros foi, se comparada a práticas de outras instituições, um passo adiante: serviu de exemplo para muitas delas que vieram conhecer o trabalho aqui realizado e entender como ele era planejado. De um modo geral, todos os pontos que devem ser cultivados no ambiente universitário citados no início deste relato estão presentes, anualmente, nas programações dos diferentes cursos. $\mathrm{O}$ cuidado em deixar explícito que o aluno ingressante deve ser respeitado em todas as suas decisões é sempre salientado nos materiais divulgados pelas diferentes unidades.

Ainda que alguns autores repudiem a expressão "trote solidário", um tipo de trote voltado para ações humanitárias (DONATO, 2015; ALMEIDA JÚNIOR \& QUEDA, 2003), essa prática está presente em diferentes situações: doações de alimentos, de sangue e na ajuda a instituições voltadas à assistência social. A necessidade de capturar a solidariedade nos alunos ingressantes aparece em cursos de todas as áreas da USP. Paralelamente, a sugestão de humanização da semana de recepção aos calouros propõe discutir e levar adiante um processo de mudança no procedimento fim desta iniciativa, 
com vista a se operar o trânsito da ética individual à ética coletiva (FIGUEIRA JUNIOR, 2006). A humanização, a partir de diretrizes e princípios, leva a interrogar práticas cotidianas, valorizar e envolver todos os atores, o que proporciona transformações. Envolve, assim, aspectos éticos, estéticos e políticos (SEIXAS, 2006). Humanismo que não pode desprezar, por exemplo, a formação de um engenheiro com visão social que, em qualquer campo e atividade, deve atuar sobre a realidade social e poder modificá-la (GRINOVER, 2008).

\section{Considerações Finais}

Pode-se afirmar que, ao longo dos dezoito anos de cuidados com as semanas de recepção aos calouros e com o Disque-Trote, claramente ocorreu mudança de cultura em todos os setores da universidade quanto à acolhida dos alunos ingressantes. Hoje as unidades estruturam, de modo atento, equipes voltadas à organização das respectivas semanas de recepção aos calouros. Docentes, discentes e funcionários se engajam em diferentes momentos das atividades programadas, que se iniciam por meio da transmissão das informações institucionais dos cursos, passam por atividades recreativas, esportivas, gincanas, oficinas culturais e chegam aos debates científicos, sociais e políticos de temas diversos. Ainda que existam prêmios para as melhores semanas, entende-se não serem eles a mola propulsora do processo nas unidades, mas sim a seriedade e o envolvimento de todos os participantes e a crença de que essa é a maneira correta de se recepcionar os novos alunos. Claro que ainda há exceções e focos de resistência que ainda insis- tem na manutenção de práticas egoístas, violentas e constrangedoras de demonstrações de hierarquia, força e poder, mas que no futuro, com certeza, serão lembradas apenas como desvios de seres que se consideravam humanos.

\section{Referências Bibliográficas}

ALMEIDA JÚNIOR, Antônio Ribeiro \& QUEDA, O. Trote na Esalq. Piracicaba: ESALQ, 2003, 144 p.

DONATO, Mauro. "Por que os Trotes Nunca Vão Acabar". Diário do Centro do Mundo, 24 fev. 2015. Disponível: < http://www.diariodocentrodomundo.com. br/por-que-os-trotes-nunca-vao-acabar $>$. Acessado em: 08 mar. 2016.

FIGUEIRA JUNIOR, Nelson. "Experiências de Gestão e Humanização Loco-regional". Boletim do Instituto Saúde, n. 39, ago. 2006, pp. 23-25.

GRINOVER, Ada Pellegrini. "Os Desafios da Gestão 1998-2001 e os Novos Desafios da Graduação". In: PEREIRA, Paulo César Xavier. Vinte Anos da Criação das Pró-reitorias na Universidade de São Paulo. São Paulo: Edusp, 2008.

PENIN, Sonia T. S. "Pró-reitoria de Graduação 2002-2005 - reflexões". In: PEREIRA, Paulo César Xavier. Vinte Anos da Criação das Pró-reitorias na Universidade de São Paulo. São Paulo: Edusp, 2008.

SEIXAS, Paulo Henrique D'Ângelo \& ABREU, Cleusa Gomes de. "Editorial". Boletim do Instituto Saúde, n. 39 , ago. 2006 , p. 5 .

UNIVERSIDADE DE SÃO PAULO. Institucionaliza, na Universidade de São Paulo, a Semana de Recepção aos Calouros. Portaria GR n. 3143, de 10 de dezembro de 1998. Disponível em: <http://www.leginf.usp. $\mathrm{br} /$ ?portaria= portaria-gr-no-3143-de-10-de-dezembro-de-1998>. Acessado em 17 mar. 2016.

UNIVERSIDADE DE SÃO PAULO. Reitoria da USP. Proíbe o Trote na Universidade de São Paulo. Portaria GR n. 3154, de 27 de abril de 1999. Disponível em: <http://www.leginf.usp.br/?portaria=portaria-gr-no-3154-de-27-de-abril-de-1999>. Acessado em 15 mar. 2016

Publicado em 05/07/2016. 
